\title{
Model dan Simulasi Alur Rantai Pasok Sampah Organik Menjadi Pakan Ternak Lele
}

\author{
Ratih Setyaningrum ${ }^{* 1}$, Dewi Agustini ${ }^{2}$, Rudi Tjahyono ${ }^{3}$, Dian Retno Sawitri ${ }^{4}$, \\ Tambah Ayu Arida ${ }^{5}$ \\ 1,2,3,5Program Studi Teknik Industri, Universitas Dian Nuswantoro, \\ Jalan Nakula 1 no 5-11 Semarang \\ ${ }^{4}$ Program Studi Teknik Elektro, Universitas Dian Nuswantoro, \\ Jalan Nakula 1 no 5-11 Semarang \\ e-mail: ${ }^{1}$ ratihha@gmail.com,${ }^{2}$ dewi@dsn.dinus.ac.id,${ }^{3}$ rudytjahyono@yahoo.co.id, \\ ${ }^{4}$ drsawitri@gmail.com, ${ }^{5}$ tambahayuard@gmail.com
}

(artikel diterima: 06-03-2020, artikel disetujui: 07-06-2020)

\begin{abstract}
Abstrak
Sampah yang paling banyak dihasilkan adalah sampah organik yaitu sebanyak $60 \%$ dibandingkan jenis sampah yang lain. Sejauh ini NRC sudah mampu mengolah sampah organik untuk dijadikan produk pakan ternak lele atau pelet. Kapasitas produksi yang mampu dilakukan perusahaan NRC yaitu sebanyak $150 \mathrm{~kg}$ sampai $200 \mathrm{~kg}$ per hari, namun sampah organik yang diperoleh saat ini belum mampu mencapai kapasitas produksi yang diperlukan. Berdasakan hal tersebut, maka perlu diusulkan model rantai pasok sampah organik yang lebih baik untuk perusahaan NRC. Tujuan penelitian ini akan memetakan rantai pasok sampah organik menjadi pakan ternak lele. Model rantai pasok yang dibuat yaitu rantai pasok kondisi saat ini dan rantai pasok usulan. Luaran akhir penelitian akan membandingkan kondisi saat ini dan usulan model rantai pasok yang dibuat. Hasil simulasi dengan software arena menunjukkan perolehan sampah organik sebanyak $352 \mathrm{~kg}$. Hal itu berarti sampah organik yang diperoleh perusahaan NRC dari ke-4 bank sampah yaitu sebanyak $352 \mathrm{~kg}$. Rekomendasi usulan rantai pasok memiliki 4 supplier bank sampah dengan setiap bank memiliki minimal 3 penghasil sampah.
\end{abstract}

Kata kunci: sampah organik, rantai pasok, simulasi.

\begin{abstract}
The most widely generated waste is organic waste, which is $60 \%$ compared to other types of waste. So far, NRC has been able to process organic waste to be used as animal feed products for catfish or pellets. The production capacity that can be carried out by the NRC company is $150 \mathrm{~kg}$ to $200 \mathrm{~kg}$ per day, but the organic waste obtained at this time has not been able to reach the required production capacity. Based on this, it is necessary to propose a better organic waste supply chain model for NRC companies. The purpose of this study will be to map the supply chain of organic waste into catfish feed. The supply chain model made is the current supply chain and the proposed supply chain. The final output of the study will compare current conditions and proposed supply chain models. The simulation results with arena software show the acquisition of organic waste as much as 352 $\mathrm{kg}$. That means organic waste obtained by the NRC company from the 4 waste banks is 352 $\mathrm{kg}$. Recommended supply chain recommendations have 4 waste bank suppliers, with each bank having a minimum of 3 waste producers.
\end{abstract}

Keywords: organic waste, supply chain, simulation. 


\section{PENDAHULUAN}

Sampah yang menumpuk dalam jumlah besar dibeberapa negara menjadi permasalahan. Sampah dibedakan menjadi organik dan anorganik. Sampah yang paling banyak dihasilkan adalah sampah organik yaitu sebanyak $60 \%$, sampah plastik sebanyak 14\%, sampah kertas sebanyak 9\%, sampah metal sebanyak 4,3\%, sampah kaca, kayu dan bahan lainnya sebanyak 12,7\%. Hal ini berarti sebanyak $24 \%$ sampah di Indonesia masih belum terkelola karena sekitar 65 juta ton sampah yang diproduksi di Indonesia setiap harinya, sekitar 15 juta ton sampah telah mencemari ekosistem dan lingkungan. Dan hanya sebanyak 7\% sampah yang didaur ulang sedangkan sebanyak 69\% sampah hanya dibiarkan menumpuk di tempat pembuangan akhir (BPS,2019).

Salah satu perusahaan yang bergerak dibidang pengelolaan sampah adalah Nusantara Recycling Center (NRC). Karena adanya permasalahan sampah tersebut, maka NRC akan membentuk suatu divisi untuk mengolah kembali sampah organik guna mengurangi penumpukan sampah yang ada dan memiliki nilai guna. Sejauh ini NRC sudah mampu mengolah sampah organik untuk dijadikan produk pakan ternak lele atau pelet. Data perolehan sampah organik perusahaan NRC disajikan padaapat dilihat pada Gambar 1.

Penelitian pendahulu mengenai rantai pasok telah diaplikasikan di beberapa bidang industri elektronik (Ninlawan et al., 2010), green supply chain management di manufaktur China (Zhu and Sarkis, 2005), beberapa penelitian juga menggabungkan antara supply chain management, environmental management, and performance management (Hervani, Helms and Sarkis, 2005). Berdasarkan review lirature tersebut menunjukkan bahwa penelitian green supply chain banyak dilakukan di berbagai bidang manufaktur.

Tujuan penelitian ini akan memetakan rantai pasok sampah organik menjadi pakan ternak lele. Model rantai pasok yang dibuat yaitu rantai pasok kondisi saat ini dan rantai pasok usulan. Luaran akhir penelitian akan membandingkan kondisi saat ini dan usulan model rantai pasok yang dibuat. 


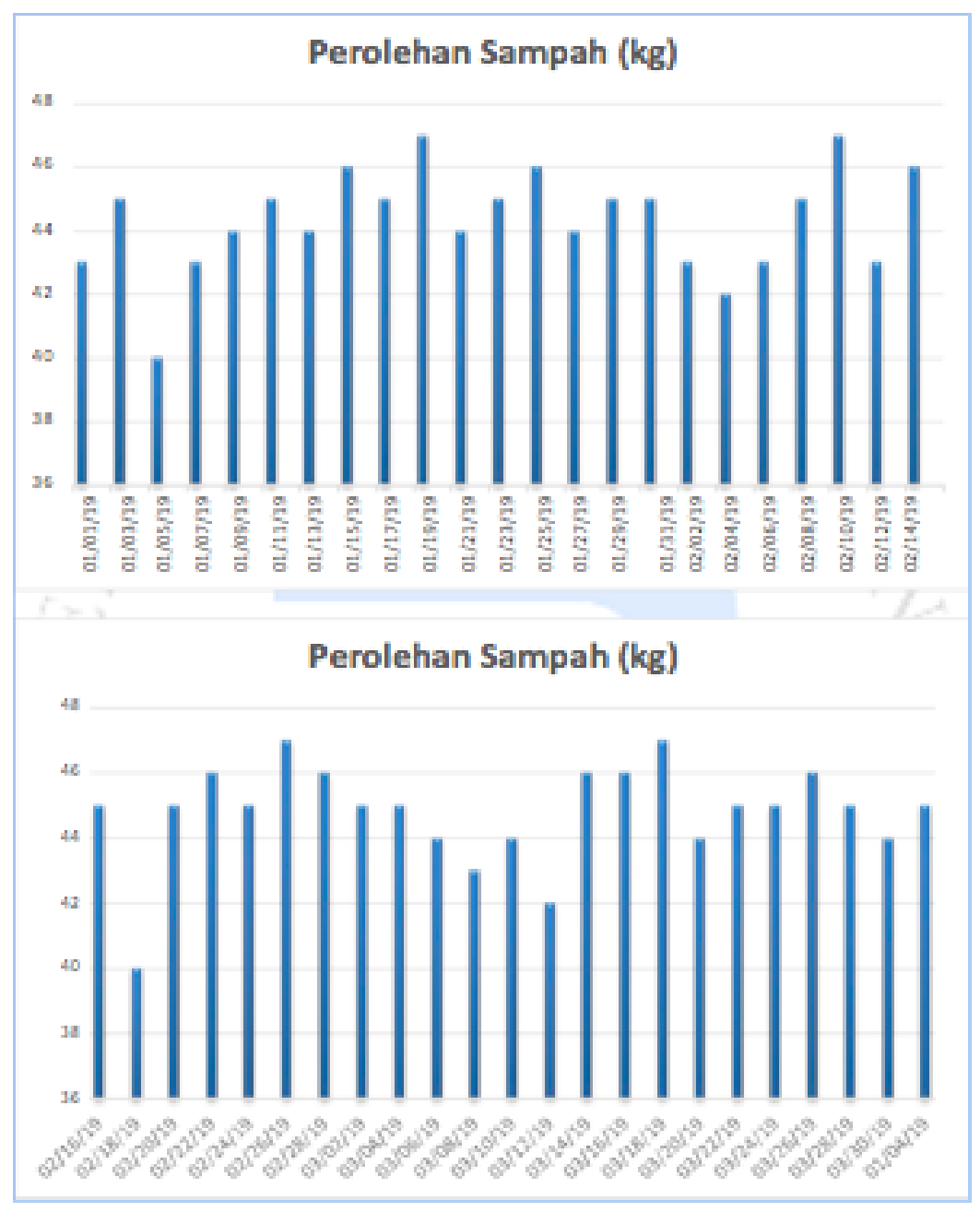

Gambar 1. Data perolehan sampah organik perusahaan NRC

\section{METODE PENELITIAN}

Penelitian ini akan mengidentifikasi rantai pasok sampah organik menjadi pakan lele (pelet), kemudian membangun model dan simulasi menggunakan sofware arena. Tahap akhir penelitian ini akan membandingkan kondisi rantai pasok saat ini dan rantai pasok usulan.

\subsection{Objek dan data penelitian}

Penelitian dilaksanakan di CV. Nusantara Recycling Center yang berlokasi di Jalan Gedong Songo 2 no 27, Manyaran, Semarang Barat 50149, Kota Semarang, Jawa Tengah. Data penelitian yaitu data kapasitas produksi, alur sampah saat ini dan data pemasok atau penghasil sampah. Sedangkan data sekunder antara lain banyaknya sampah organik atau kapasitas sampah organik yang ada di Kota Semarang, jumlah transportasi yang digunakan dan persentase sampah organik.

\subsection{Manajemen Rantai Pasok}

Proses bisnis di dalam rantai dapat dilihat dari dua pandangan, kedua pandangan tersebut adalah cycle view dan push or pull view (Na, Me and Meindl, 
2007). Cycle view menjelaskan bahwa terdapat beberapa siklus dimana setiap siklusnya terjadi di antara dua anggota rantai pasok berhadapan disajikan pada Gambar 2. Push or pull view menjelaskan bahwa terdapat dua kategori pandangan tergantung pada tindakan anggota rantai pasok dalam merespon pesanan (permintaan) konsumen atau sebagai tindakan antisipasi dari permintaan konsumen.

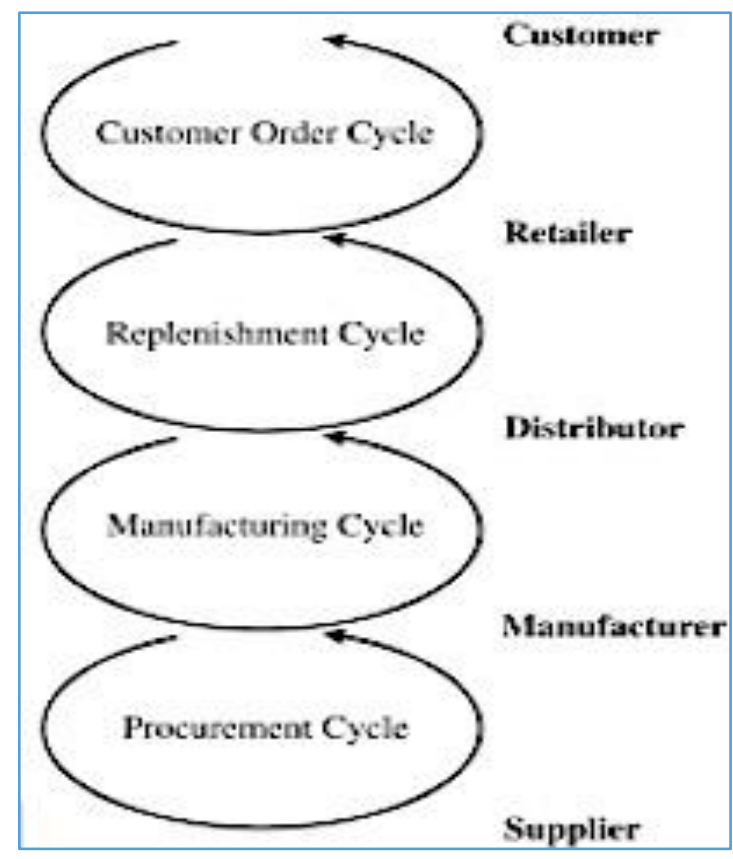

Gambar 2. Siklus Proses Cycle View Rantai Pasok

Pemain utama manajemen rantai pasok pada penelitian ini yaitu Rantai 1 - 2: Pemasok - Manufaktur. Rantai pertama dihubungkan dengan rantai kedua yaitu manufaktur atau pabrik. Manufaktur melakukan pekerjaan membuat, memfabrikasi, merakit, mengkonversikan atau menyelesaikan barang. Hubungan dengan mata rantai pertama mempunyai potensi untuk melakukan penghematan. Misalnya, persediaan bahan baku, bahan setengah jadi, dan bahan jadi yang berada di pihak pemasok, manufaktur, dan tempat transit merupakan target penghematan. Penghematan sebesar 40-60 persen dapat diperoleh dengan menggunakan konsep kemitraan dengan pemasok.

\subsection{Simulasi Rantai Pasok dengan Arena}

Pada tahap ini maka akan dilakukan pembuatan model simulasi mengenai model rantai pasok sampah organik yang terdapat pada penelitian yang dilakukan yaitu alur SCM Kondisi Saat ini dan Usulan Alur SCM yang di usulkan oleh peneliti kepada Perusahaan NRC.

Dalam melakukan simulasi terdapat lima langkah pokok yang perlu diperhatikan yaitu:

1. Menentukan masalah

2. Memformulasikan model simulasi 
3. Melakukan uji model simulasi lalu membandingkan tingkah laku sistem baru dengan tingkah laku sistem nyata

4. Melakukan percobaan-percobaan terhadap model simulasi

5. Menjalankan simulasi dan analisa data

\subsection{Analisis dan Pembahasan Model dan Simulasi Rantai Pasok dengan Arena}

Model Rantai pasok kondisi saat ini dijelaskan alur dan simulasi model rantai pasok kemudian dievaluasi dan dilakukan rekomendasi simulasi rantai pasok usulan. Perbandingan kondisi rantai pasok saat ini dan usulan dikaji berdasarkan hasil simulasi software Arena.

\section{HASIL DAN PEMBAHASAN}

Data pemasok sampah organik yang akan menjadi pemasok sampah organik bagi perusahaan NRC, dapat dilihat pada Tabel 1.

Tabel 1. Pemasok Sampah Organik

\begin{tabular}{ll}
\hline No & Penghasil Sampah \\
\hline 1 & Sampah Pemulung/Pengepul \\
2 & Sampah HOREKA \\
3 & Sampah Rumah Sakit \\
\hline
\end{tabular}

Kapasitas produksi yang mampu dilakukan perusahaan NRC yaitu sebanyak $150 \mathrm{~kg}$ sampai $200 \mathrm{~kg}$ per hari, namun sampah organik yang diperoleh saat ini belum mampu mencapai kapasitas produksi yang diperlukan. Sampah organik yang diperoleh selama 3 bulan yaitu sebanyak $2050 \mathrm{~kg}$, rata-rata produksi sampah tiap harinya yaitu sebanyak $46 \mathrm{~kg}$. Harga olahan sampah organik yang dijadikan pakan lele yaitu Rp 6.000 per kg. Pendapatan kotor perusahaan NRC sebanyak Rp 276.000. Berikut ini alur proses dari sampah organik di supply kemudian proses pengolahan sampah plastik menjadi pakan lele hingga disalurkan ke prusahaan CV Mina Jaya disajikan pada Gambar 3.

Model simulasi rantai pasok saat ini terdiri dari beberapa proses diantaranya yaitu, pengumpulan sampah organik dari satu pemasok di NRC, setelah itu di dalam NRC terdapat proses pemeliharaan larva (larva - menjadi prepupa - pupa dewasa). Kemudian proses selanjutnya yaitu proses penggilingan bahan untuk dijadikan tepung - proses pencampuran bahan lain - proses pencetakan - proses pengeringan yang kemudian menjadi pellet (pakan ternak lele) - dan dijual ke CV. Mina Jaya, dapat dilihat pada Gambar 4. Hasil simulasi rantai pasok kondisi NRC saat ini disajikan pada Gambar 5. Kondisi tersebut belum memenuhi jumlah pasokkan sampah organik yang diperlukan untuk berproduksi, sehingga dapat disimpulkan kondisi saat ini pasokan material pakan lele masih kurang. Oleh sebab itu perlu diberikan rekomendasi usulan rantai pasok agar mampu berproduksi sesuai kapasitas NRC dan memenuhi demand CV Mina Jaya. 


\section{NRC (sampah} organik)

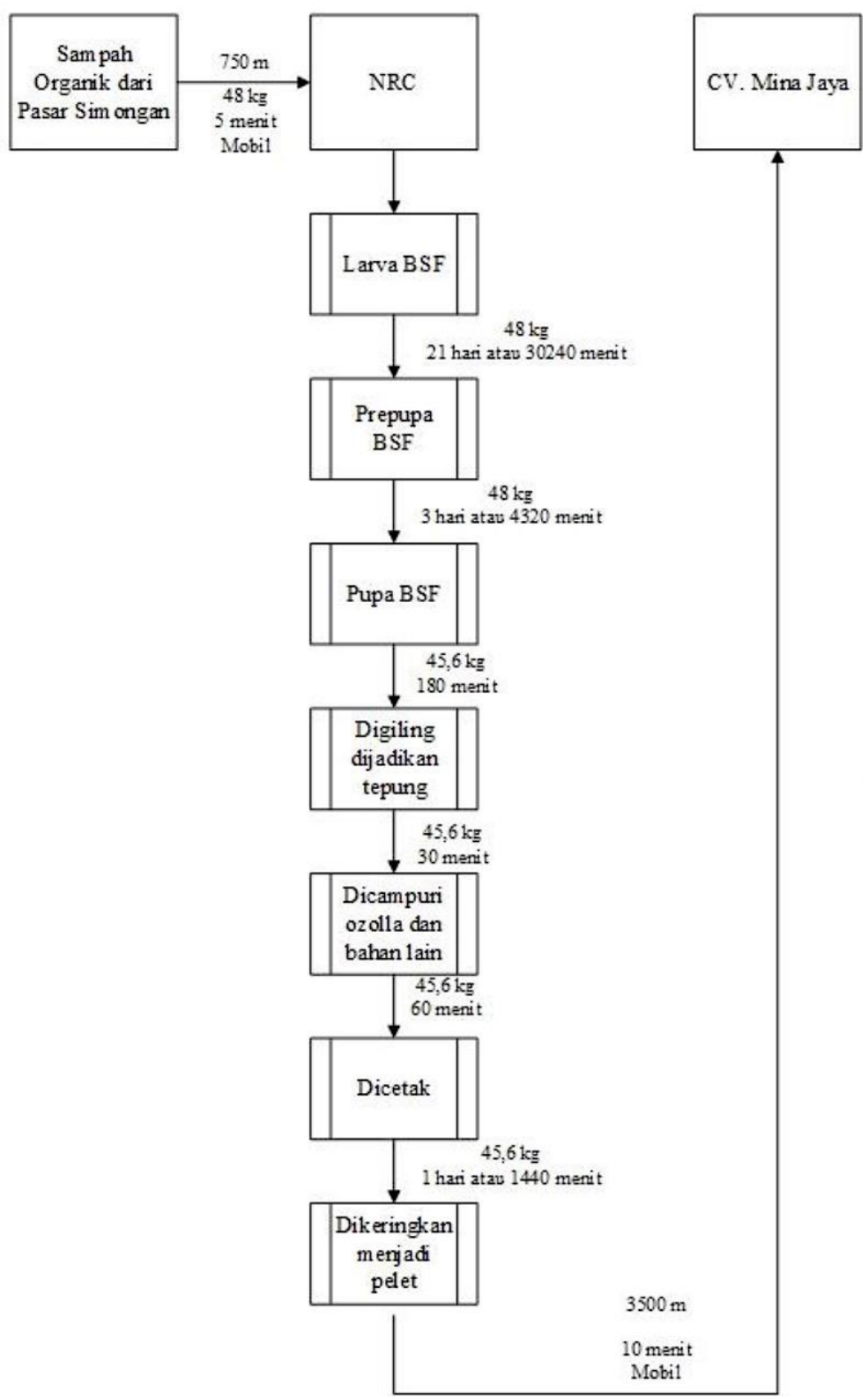

Gambar 3. Rantai pasok dari Supplier-manufaktur- retail 


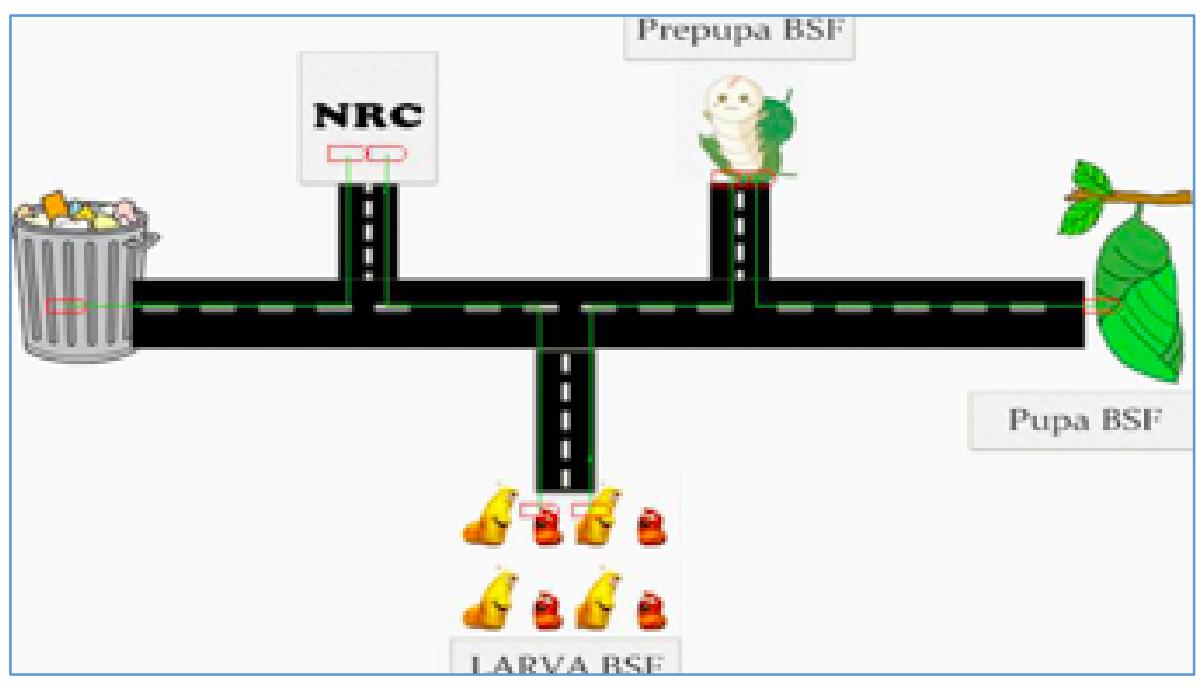

Gambar 4. Alur rantai pasok saat ini

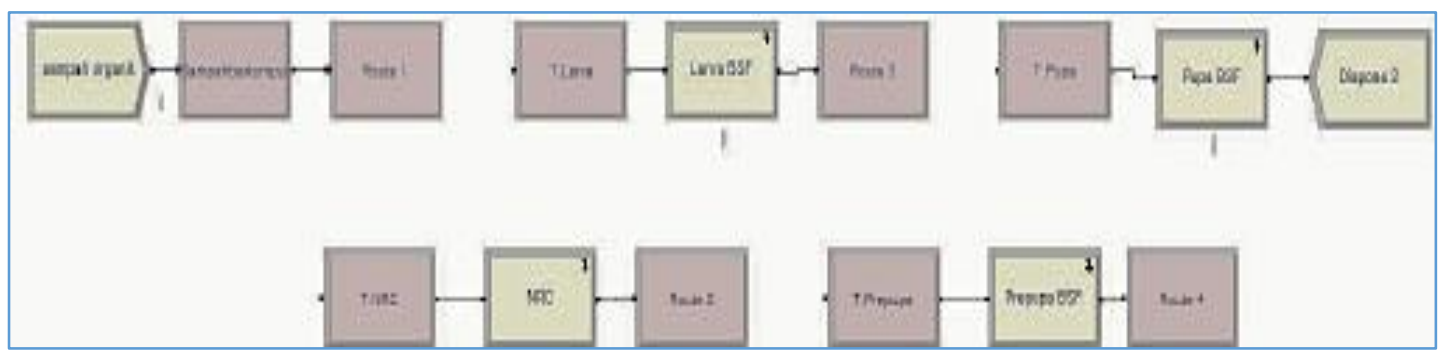

Gambar 5. Hasil simulasi rantai pasok kondisi saat ini dengan sotware arena

Perusahaan NRC memiliki kapasitas produksi yang cukup banyak yaitu sebanyak $150 \mathrm{~kg}$ sampai $200 \mathrm{~kg}$, proses pengolahan tersebut dilakukan setiap 2 hari sekali dengan jam kerja 8 jam. Namun hasil Output yang diperoleh yaitu sebanyak $46 \mathrm{~kg}$. Itu artinya, sampah organik yang diperoleh.

Berdasarkan kondisi rantai pasok sampah organik yang NRC saat ini, maka perlu diusulkan model rantai pasok sampah organik yang lebih baik untuk perusahaan NRC. Rantai pasok usulan harus melibatkan aspek sosial, ekonomi dan lingkungan di perusahaan NRC (Smith and Rupp, 2003). Usulan model rantai pasok sampah organik ini akan membentuk 4 bank sampah dimasing-masing wilayah diantaranya semarang tengah, semarang utara, semarang timur dan semarang selatan. Dan setiap bank sampah akan memiliki beberapa penghasil sampah yang akan menyetorkan sampah organik tersebut ke bank sampah. Setelah sampah terkumpul di bank sampah maka perusahaan NRC akan mengambil sampah tersebut untuk diolah menjadi pakan ternak lele atau pelet. Hasil alur rantai pasok usulan untuk perusahaan NRC disajikan pada Gambar 6 (a) dan Gambar 6 (b) sedangkan hasil simulasi rantai pasok usulan dengan software arena disajikan pada Gambar 7. 


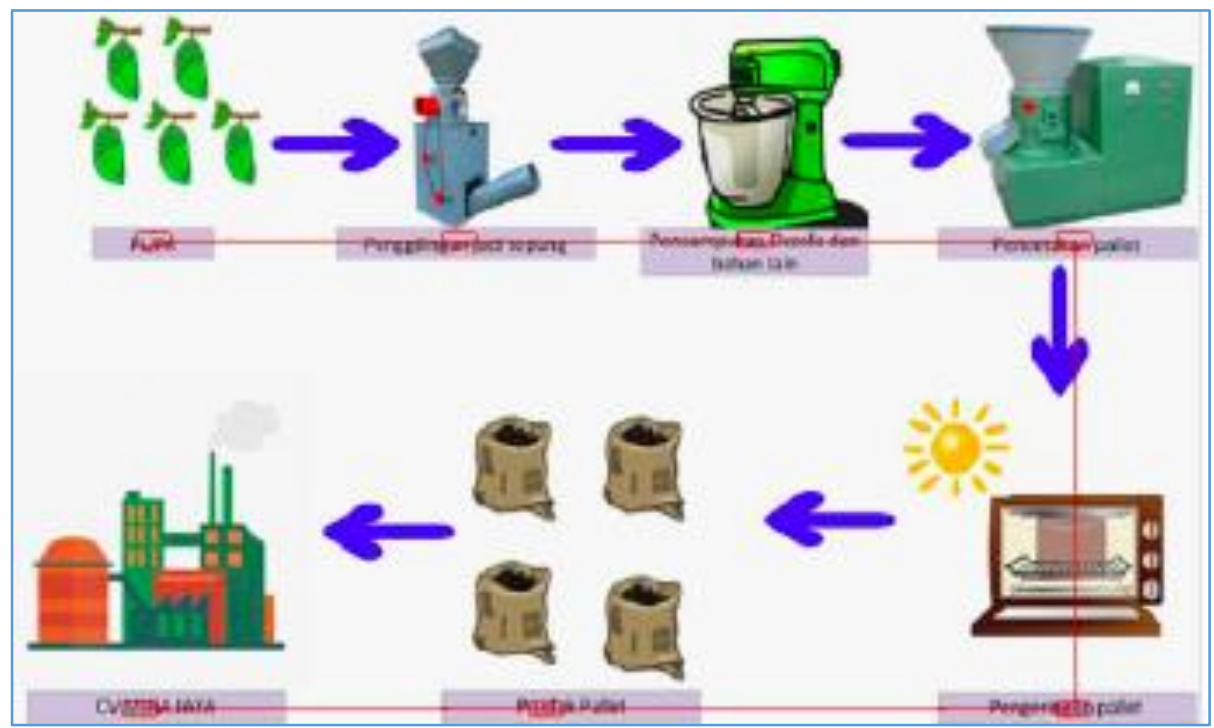

Gambar 6 (a). Hasil alur rantai pasok usulan

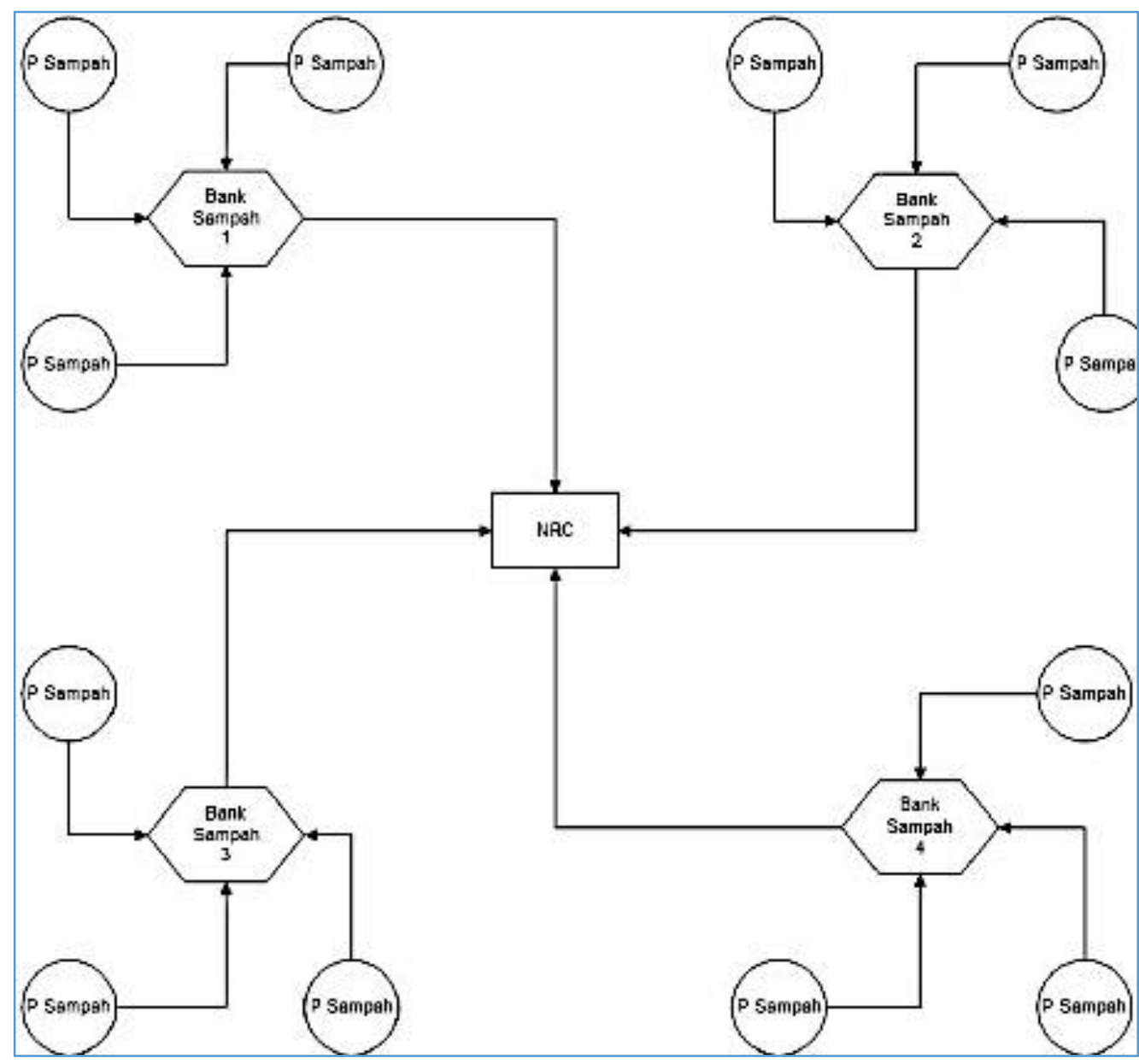

Gambar 6 (b). Hasil alur rantai pasok usulan 


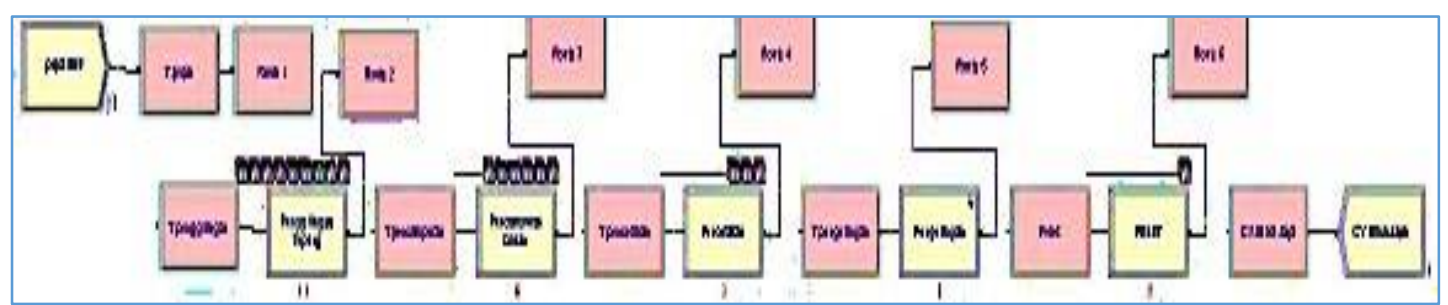

Gambar 7. Hasil simulasi rantai pasok usulan dengan software arena

Usulan model rantai pasok sampah organik ini dapat dikatakan layak, karena berdasarkan simulasi pada Gambar 7 dengan menggunakan software arena output hasil sampah organik yang diperoleh sangat mencukupi kapasitas yang diperlukan oleh perusahaan NRC yaitu sebanyak $352 \mathrm{~kg}$ per hari. Hal tersebut secara tidak langsung akan meningkatkan keuntungan yang dapat diperoleh oleh perusahaan NRC.

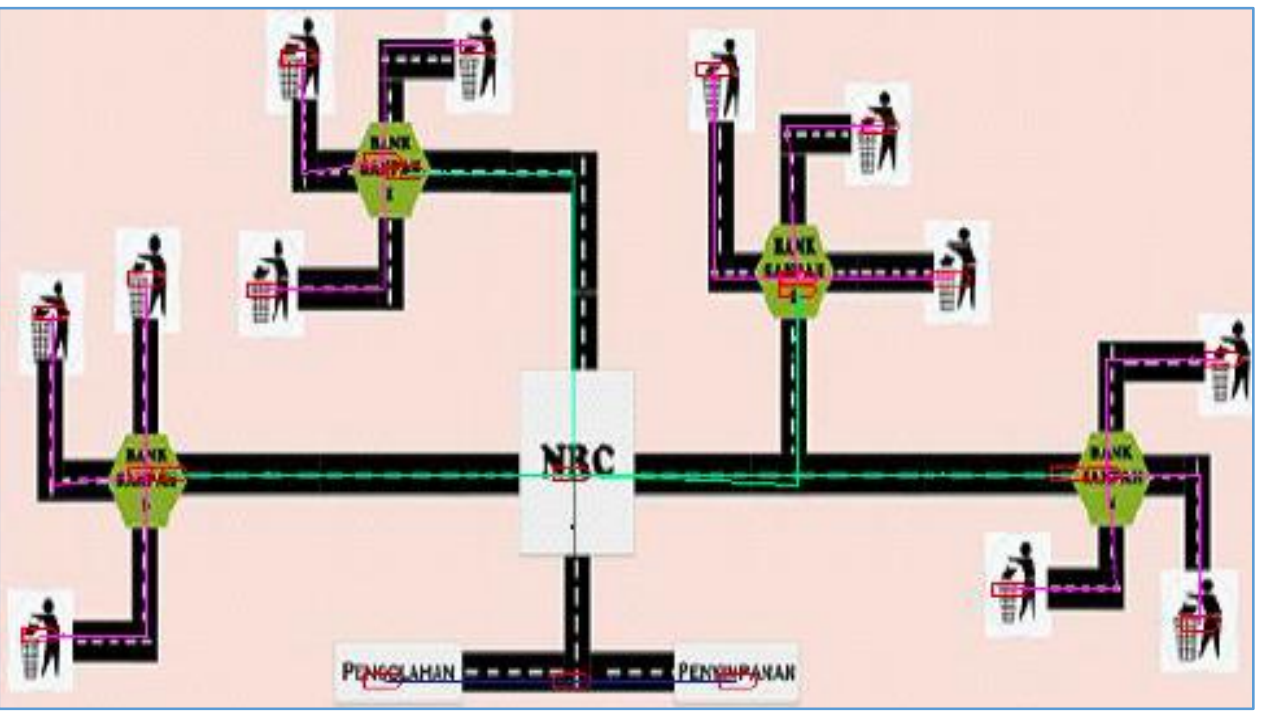

Gambar 8 (a). Hasil output simulasi rantai pasok dengan software Arena

\begin{tabular}{lc} 
Total Number Seized & Value \\
\hline gudang & 179.00 \\
nrc1 & 35200 \\
pengolahan1 & 17300
\end{tabular}

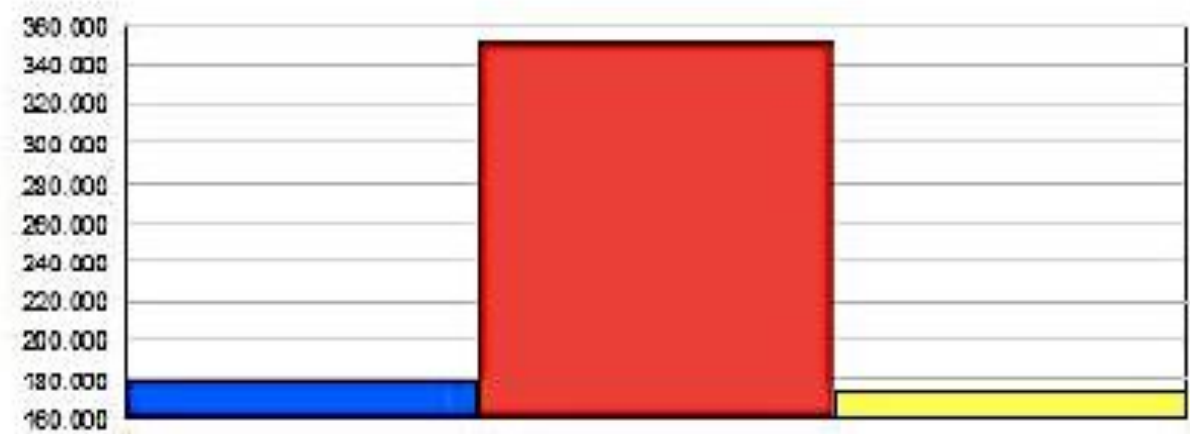

Gambar 8 (b). Hasil output simulasi rantai pasok dengan software Arena 
Hasil simulasi dengan software arena yang disajikan pada Gambar 8 (a) dan Gambar 8 (b) menunjukkan perolehan sampah organik sebanyak $352 \mathrm{~kg}$. Hal itu berarti sampah organik yang diperoleh perusahaan NRC dari ke-4 bank sampah yaitu sebanyak $352 \mathrm{~kg}$. Berdasarkan simulasi maka sampah organik yang dapat diolah oleh perusahaan NRC yaitu sebanyak $173 \mathrm{~kg}$. Sedang sampah organik yang ditampung yaitu sebanyak $197 \mathrm{~kg}$. Dari hasil usulan yang disimulasikan tersebut berpotensi akan meningkatkan keuntungan NRC.

Luaran penelitian ini merekomendasikan alur rantai pasok sampah organik menjadi pakan ternak lele di perusahaan NRC. Disamping itu, rantai pasok ini dapat diacu untuk proses manajemen pengelolaan sampah organik di wilayah lain, sekaligus menunjukkan alur green supply chain (Kumar and Kumar, 2013). Manajemen rantai pasok perlu dioptimalkan untuk memperbaiki proses produksi ; Smith and Rupp, 2003). Pada perusahaan NRC manajemen rantai pasok yang direkomendasikan untuk memenuhi kapasitas produksi.

\section{KESIMPULAN}

Model usulan rantai pasok untuk perusahaan NRC yaitu pada usulan model rantai pasok terdapat beberapa 4 bank sampah organik disetiap wilayah Semarang dan disetiap bank sampah masing-masing memiliki 3 penghasil sampah. Simulasi rantai pasok tersebut mampu memenuhi kapasitas produksi perusahaan NRC sehingga akan mampu memenuhi order dari CV Mina Jaya..

\section{DAFTAR PUSTAKA}

Badan Pusat Statistik. (2019). Presentase Sampah di Kota Semarang. Semarang.

Hervani, A. A., Helms, M. M. and Sarkis, J. (2005) 'Performance measurement for green supply chain management'Benchmarking: An International Journal, No. 4, Vol 12 (4), pp.330-353. doi: 10.1108/14635770510609015

Kumar, N. R. and Kumar, R. M. S. (2013) 'Closed Loop Supply Chain Management and Reverse Logistics -A Literature Review', International Journal of Engineering Research and Technology, No.4, Vol 6, pp. 455-468.

Na, M. A., Me, G. E. and Meindl, P. (2007) 'Supply Chain Management : Strategy and Planning, Vol 1, Ed.3, Pearson, Prentice Hall, New Jersey.

Ninlawan, C. et al. (2010) 'The Implementation of Green Supply Chain Management Practices in Electronics Industry', Proceeding of International Multi Conference of Engineer and Computer Science 2010 vol. III, Hongkong.

Smith, A. D. and Rupp, W. T. (2003) 'An examination of emerging strategy and sales performance : motivation, chaotic change and organizational structure', 21(3), pp. 156-167. doi: 10.1108/02634500310474975.

Zhu, Q. and Sarkis, J. (2005) 'Relationships between operational practices and perfor- mance among early adopters of green supply chain management practices in Chinese manufacturing enterprises. Journal of Operations 
Management, 22(3), 265-289.

Gunawan, A., 2007, Analisis Perbaikan Rantai Pasok menggunakan Sistem Dinamis, Skripsis, Program Studi teknik Industri, Univ. Islam indonesia, Yogyakarta. 